\title{
Multi-mode Li diffusion in natural zircons: Evidence for diffusion in the presence of step-function concentration boundaries
}

\author{
Ming Tang ${ }^{\mathrm{a}, \mathrm{b}, *}$, Roberta L. Rudnick ${ }^{\mathrm{a}, \mathrm{c}}$, William F. McDonough ${ }^{\mathrm{a}, \mathrm{d}}$, Maitrayee Bose ${ }^{\mathrm{e}}$, \\ Yulia Goreva ${ }^{\text {f,g }}$
}

a Department of Geology, University of Maryland, College Park, MD 20742, USA

b Department of Earth Science, Rice University, Houston, TX 77005, USA

c Department of Earth Science, University of California, Santa Barbara, CA 73106, USA

d Department of Earth Sciences, Tohoku University, Sendai, Miyagi 980-8578, Japan

e School of Earth and Space Exploration, Arizona State University, Tempe, AZ 85281, USA

${ }^{\mathrm{f}}$ Department of Mineral Sciences, Smithsonian Institute, Washington DC, 20013, USA

g NASA, Jet Propulsion Laboratory, Pasadena, CA 91109, USA

\section{A R T I C L E I N F O}

\section{Article history:}

Received 22 March 2017

Received in revised form 13 May 2017

Accepted 20 June 2017

Available online $\mathrm{xxxx}$

Editor: A. Yin

\section{Keywords:}

Li diffusion

zircon

charge coupling

geospeedometer

ToF-SIMS

NanoSIMS

\begin{abstract}
A B S T R A C T
Micron- to submicron-scale observations of Li distribution and Li isotope composition profiles can be used to infer the mechanisms of Li diffusion in natural zircon. Extreme fractionation $(20-30 \% 0)$ within each single crystal studied here confirms that Li diffusion commonly occurs in zircon. Sharp Li concentration gradients frequently seen in zircons suggest that the effective diffusivity of Li is significantly slower than experimentally determined (Cherniak and Watson, 2010; Trail et al., 2016), otherwise the crystallization/metamorphic heating of these zircons would have to be unrealistically fast (years to tens of years). Charge coupling with REE and $\mathrm{Y}$ has been suggested as a mechanism that may considerably reduce Li diffusivity in zircon (Ushikubo et al., 2008; Bouvier et al., 2012). We show that Li diffused in the direction of decreasing $\mathrm{Li} / \mathrm{Y}$ ratio and increasing Li concentration (uphill diffusion) in one of the zircons, demonstrating charge coupling with REE and Y. Quantitative modeling reveals that Li may diffuse in at least two modes in natural zircons: one being slow and possibly coupled with REE+Y, and the other one being fast and not coupled with REE+Y. The partitioning of Li between these two modes during its diffusion may depend on the pre-diffusion substitution mechanism of REE and $Y$ in the zircon lattice. Based on our results, sharp Li concentration gradients are not indicative of limited diffusion, and can be preserved at temperatures $>700^{\circ} \mathrm{C}$ on geologic timescales. Finally, large $\delta^{7} \mathrm{Li}$ variations observed in the Hadean Jack Hills zircons may record kinetic fractionation, rather than a record of ancient intense weathering in the granite source materials.
\end{abstract}

(c) 2017 Elsevier B.V. All rights reserved.

\section{Introduction}

Lithium and its isotopes $\left({ }^{6} \mathrm{Li}\right.$ and $\left.{ }^{7} \mathrm{Li}\right)$ have seen a wide range of applications in geoscience (Tomascak et al., 2016; PennistonDorland et al., 2017). On one hand, Li isotopes can be a powerful tracer of chemical weathering (Chan et al., 1992; Pistiner and Henderson, 2003; Rudnick et al., 2004; Liu et al., 2013; Dellinger et al., 2017). On the other hand, the rapid diffusivity of $\mathrm{Li}$ and the associated large kinetic isotopic fractionations make Li a promising geospeedometer for determining rates of rapid geologic processes that can be difficult to determine using other

\footnotetext{
* Corresponding author.

E-mail address: tangmyes@gmail.com (M. Tang).
}

geospeedometers (e.g., Richter et al., 2003; Jeffcoate et al., 2007). Resolving the roles of equilibrium vs. kinetic mechanisms in driving $\mathrm{Li}$ isotopic fractionation is critical when applied to $\mathrm{Li}$ isotopic studies and understanding the geologic processes recorded by these data.

The Li isotopic composition of Hadean zircons has been interpreted to reflect intense chemical weathering during the earliest portion of Earth history (Ushikubo et al., 2008). Ushikubo et al. (2008) and Bouvier et al. (2012) argued that Li atoms are charge coupled with slow-diffusing REE and $\mathrm{Y}$ atoms in the zircon lattice, thereby inhibiting Li diffusion under most geological P-T-X conditions (i.e., pressure, temperature and composition, including $\mathrm{H}_{2} \mathrm{O}$ content), and, thus, that zircon can preserve initial magmatic $\mathrm{Li}$ isotopic signatures. This assumption was later challenged by ex- 
perimental studies (Cherniak and Watson, 2010), which showed that Li can diffuse rapidly in zircon under crustal P-T-X conditions. Rather than using $\mathrm{Li}$ in zircon to track magmatic sources, the work by Cherniak and Watson (2010) suggested the possibility of using $\mathrm{Li}$ in zircon as a magmatic and metamorphic geospeedometer, with the first attempt made by Trail et al. (2016). Lithium diffusion in zircon was also reported by Gao et al. (2015), who studied Li isotopes in several zircon standards. Despite the evidence supporting Li diffusion in zircon under crustal P-T-X conditions, the diffusion mechanism remains elusive.

Here, we report the results of micron- to submicron-scale SIMS studies on $\mathrm{Li}$ distribution and $\mathrm{Li}$ isotope profiles in natural zircons. Our work confirms that Li diffusion occurs in zircon in the crust, and, for the first time, reveals multiple diffusion modes for $\mathrm{Li}$ in zircon that may involve charge coupling with REE $+\mathrm{Y}$.

\section{Background}

At Earth's surface Li isotopes readily undergo equilibrium fractionation because of the relatively large mass difference between ${ }^{6} \mathrm{Li}$ and ${ }^{7} \mathrm{Li}$ (17\%). They can also fractionate at high temperatures due to Li diffusion. Li isotopic compositions are typically reported in delta notation $\left(\delta^{7} \mathrm{Li}=\left(\left({ }^{7} \mathrm{Li} /{ }^{6} \mathrm{Li}\right)_{\text {sample }} /\left({ }^{7} \mathrm{Li} /{ }^{6} \mathrm{Li}\right)_{\mathrm{L}-S V E C}\right) * 1000\right)$, where L-SVEC is a Li isotope standard.

\subsection{Diffusive fractionation of Li isotopes}

Lithium isotopes can fractionate during diffusion because ${ }^{6} \mathrm{Li}$ diffuses faster than ${ }^{7} \mathrm{Li}$ and such an effect can be preserved if cooling is rapid. Richter et al. (2003) first documented diffusioninduced $\mathrm{Li}$ isotopic fractionation in an experimental study that measured a $\mathrm{Li}$ isotopic profile across the interface of two compositionally distinct end-member lithologies, molten basalt and rhyolite, and found that ${ }^{6} \mathrm{Li}$ diffuses $\sim 3 \%$ faster than ${ }^{7} \mathrm{Li}$. Later, Lundstrom et al. (2005) reported diffusive fractionation of Li isotopes in the Trinity Ophiolite. Following this, a series of studies reported Li diffusion within the country rocks adjacent to Li-rich intrusions (Teng et al., 2006; Marks et al., 2007; Liu et al., 2013), finding large and systematic Li isotopic variation over tens of meters and extremely low $\delta^{7} \mathrm{Li}$ (down to $-20 \%$ ) values, which they interpreted to be the result of diffusion-driven fractionation of $\mathrm{Li}$ isotopes. Jeffcoate et al. (2007) and Parkinson et al. (2007) observed diffusive fractionation of $\mathrm{Li}$ isotopes on a grain scale in peridotites and phenocrysts in basalt. Many additional studies of natural rocks have uncovered evidence of Li diffusion and associated isotopic fractionation, as summarized in Penniston-Dorland et al. (2017). These studies demonstrate that tens of permil fractionation of Li isotopes can be achieved by diffusion over length scales varying from millimeters to tens of meters.

\subsection{Li isotopes in zircons}

Zircon, known for its refractory nature, is the oldest known terrestrial material accessible on Earth. If zircon faithfully records magmatic Li isotopic signatures, it may extend the Li isotope probe of weathering intensity to the Hadean, a time for which other crustal materials are absent. Ushikubo et al. (2008) reported large $\delta^{7} \mathrm{Li}$ variations $(>30 \% 0$ ) in the Hadean Jack Hills zircons. Some of the zircons analyzed showed extremely low $\delta^{7} \mathrm{Li}$ (down to $-20 \% 0$ ). These authors interpreted their data to reflect incorporation of an intensively weathered component into the source region of the granite from which the zircon crystallized. Large $\delta^{7} \mathrm{Li}$ variations in zircon were also observed by Bouvier et al. (2012), who concluded that it reflected the signatures of the magma source materials.

One of the assumptions underlying the above interpretations is that $\mathrm{Li}$ isotopes do not fractionate within zircon and between
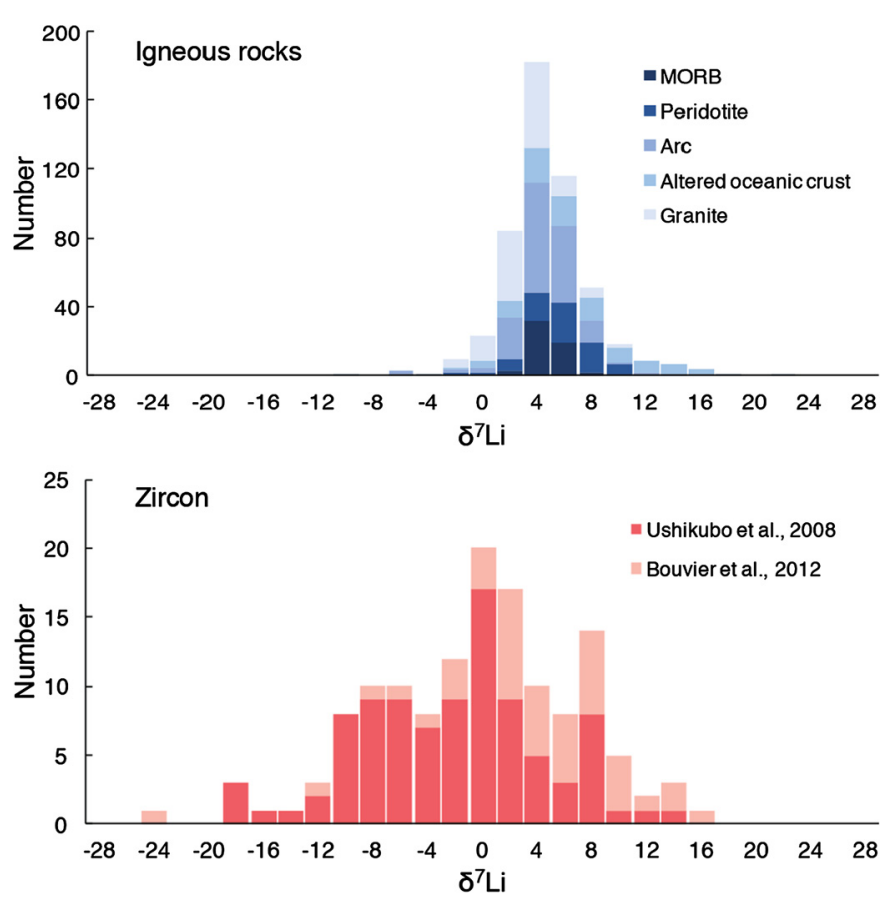

Fig. 1. Li isotopic compositions of igneous rocks and zircon. See Supplementary File 2 for a compilation of $\delta^{7} \mathrm{Li}$ in igneous rocks.

zircon and melt during and following magmatic crystallization. A number of studies have concluded that equilibrium fractionation of Li isotopes is limited during metamorphic dehydration, partial melting and fractional crystallization (Tomascak et al., 1999; Marschall et al., 2007; Teng et al., 2007, 2009; Qiu et al., 2009, 2011a, 2011b). However, it remains unclear whether or not Li diffuses, and thus creates kinetic isotope fractionation during zircon growth or metamorphic events. The range of $\delta^{7} \mathrm{Li}$ measured in zircons largely exceeds that of igneous rocks (Fig. 1), and the discrepancy mainly results from the extremely negative $\delta^{7} \mathrm{Li}$ values in the zircons. Such extreme $\delta^{7} \mathrm{Li}$ values have only been observed in highly weathered regoliths (Rudnick et al., 2004) and in rocks and minerals that experienced kinetic fractionation associated with $\mathrm{Li}$ diffusion (e.g., Teng et al., 2006; Jeffcoate et al., 2007).

Lithium isotopic compositions are spatially heterogeneous in reference zircons, with $\delta^{7} \mathrm{Li}$ ranging from $8 \%$ to $20 \%$ in these zircons: 91500, Plešovice, TEMORA 2 and BR266 (Li et al., 2011; Gao et al., 2015). These variations are significant given reported $2 \sigma$ analytical uncertainty is better than $2 \%$. Li et al. (2011) and Gao et al. (2015) also documented that these reference zircons have heterogeneous Li concentrations. These observations stand in contrast to their homogeneous $\mathrm{Hf}$ and $\mathrm{O}$ isotopic compositions.

\subsection{Experimental perspectives on Li diffusion in zircon}

Lithium may substitute in a zircon lattice by coupling with trivalent REE and Y ions (Finch et al., 2001; Hanchar et al., 2001; Ushikubo et al., 2008; Bouvier et al., 2012), and in this case, Li diffuses together with REE and Y, which will slow Li diffusivity by orders of magnitude. However, this mechanism has not been observed by current experimental studies (Cherniak and Watson, 2010; Trail et al., 2016), both of which reported fast Li diffusion in zircon. Cherniak and Watson (2010) conducted "in" diffusion experiments using REE-depleted Mud Tank zircons, and thus their experiments are unlikely to have evaluated charge coupling effects. Using Lu- and P-doped synthetic zircons, Trail et al. (2016) carried out "in" diffusion and heating experiments, and their "in" diffusion experiments showed no discernable difference in Li diffusivity when compared to Cherniak and Watson's results. These 
Table 1

REE and Y substitution in zircon.

\begin{tabular}{ll}
\hline Equations & References \\
\hline $\mathrm{Li}^{+}{ }_{\text {(interstitial) }}+(\mathrm{Y}+\mathrm{REE})^{3+}=\mathrm{Zr}^{4+}$ & Finch et al. (2001), \\
& Hanchar et al. (2001) \\
$(\mathrm{Y}+\mathrm{REE})^{3+}+\mathrm{P}^{5+}=\mathrm{Zr}^{4+}+\mathrm{Si}^{4+}$ & Speer (1982) \\
$\mathrm{H}^{+}{ }_{(\text {interstitial })}+(\mathrm{Y}+\mathrm{REE})^{3+}=\mathrm{Zr}^{4+}$ & Trail et al. (2011), \\
& De Hoog et al. (2014) \\
$(\mathrm{Mg}, \mathrm{Fe})^{2+}+3(\mathrm{Y}+\mathrm{REE})^{3+}+\mathrm{P}^{5+}=3 \mathrm{Zr}^{4+}+\mathrm{Si}^{4+}$ & Hoskin et al. (2000) \\
$(\mathrm{Al}, \mathrm{Fe})^{3+}+4(\mathrm{Y}+\mathrm{REE})^{3+}+\mathrm{P}^{5+}=4 \mathrm{Zr}^{4+}+\mathrm{Si}^{4+}$ & Hoskin et al. (2000) \\
\hline
\end{tabular}

experimental studies reveal that another substitution mechanism for Li in zircon that does not involve coupling with REE and Y creates a fast diffusion mode. On the other hand, the current diffusion experiments do not negate a charge coupling mechanism between and $\mathrm{Li}$ and REE+Y. REE and Y may enter the zircon lattice via multiple substitution mechanisms (Table 1). As Li diffuses in zircon, the coupling between $\mathrm{Li}$ and $\mathrm{REE}+\mathrm{Y}$ may take place as exchange reactions. Therefore, the reaction constant, or the likelihood of the coupling between $\mathrm{Li}$ and $\mathrm{REE}+\mathrm{Y}$, will be sensitive to the pre-diffusion substitution mechanisms of REE+Y. If Li substitution employs multiple mechanisms in the zircon lattice, it may have several diffusion modes and the bulk Li diffusion behavior will be the sum of its diffusivity in each mode and its partitioning between different modes.

\section{Samples}

The samples studied here include one zircon grain from a Tanzania lower crustal granulite xenolith (LB04-19-02), three zircon grains from Archean tonalite-trondhjemite-granodiorites (TTGs) (DD81-32-6-8, C88-29-7-6 and DD86-25a-3-6) and two zircon grains from a sanukitoid (DD96-10-4-8 and DD96-4-5-11). Details for the Tanzanian sample (whole rock data, mineral chemistry data, $\mathrm{U}-\mathrm{Pb}$ dates, in situ $\mathrm{Pb}$ isotopic results and thermobarometry) are given in Bellucci et al. (2011) and Mansur et al. (2014), and for the remaining samples are given in Bouvier et al. (2012). All natural zircons were imaged by ToF-SIMS (Time of Flight Secondary Ion Mass Spectrometry) for multi-element distributions including those of Li and Y. Lithium isotope profiles were then measured on all three TTG zircons and one sanukitoid zircon (DD96-4-5-11). The TTG and sanukitoid zircons were previously characterized by CL (cathodoluminescence) imaging and SIMS spot analyses for their Li isotope and trace element compositions (Bouvier et al., 2012). We did not attempt to analyze Li isotopes in the zircon from the granulite xenolith due to its very low Li concentration ( $<0.2 \mathrm{ppm})$.

\section{Methods}

\subsection{Cathodoluminescence imaging}

Fine details of crystal zoning are often only visible in CL. Before analyses, monochromatic CL images (Fig. 3) of zircon grains were obtained at the Smithsonian Institution, Mineral Sciences Department using a FEI Nova NanoSEM 600, a scanning electron microscope coupled to an ultra-high-resolution field emission gun and fitted with a Gatan cathodoluminescence detection system.

\subsection{ToF-SIMS imaging}

For all natural zircons ion imaging was performed at the Smithsonian Institution using the ION TOF GmbH IV TOF-SIMS instrument (Figs. 3 and 4). Surface pre-sputtering was done using a $30 \mathrm{nA}$ Ar current in a $500 \mu \mathrm{m} \times 500 \mu \mathrm{m}$ square area. An electron flood gun was used for charge compensation at the sputtering site. A $25 \mathrm{keV} \mathrm{Bi}^{+}$source was used as the primary beam and two types of ion imaging techniques were employed:

(1) For whole grain imaging, we used the "High Current Bunched" mode with high mass/low spatial resolution. The pulsed target current was $0.3 \mathrm{pA}$ and mass resolution (M/delta-M) was $\sim 8000$ at $30 \mathrm{amu}$, with a $\sim 2 \mu \mathrm{m}$ spot size. The image raster size varied with the imaged grain size, achieving an image resolution of $256 \times 256$ pixels;

(2) For local (core-rim boundary or crystal interface) imaging, we used the "Burst Alignment" mode with high spatial/low mass resolution to obtain a lateral resolution of $200-400 \mathrm{~nm}$ and mass resolution of $1 \mathrm{amu}$. The pulsed target current was $0.05 \mathrm{pA}$. Extralong 200 ns pulses were used to enhance the Li signal. Image raster size was $100 \times 100 \mu \mathrm{m}$ with an image resolution of $512 \times 512$ pixels.

\subsection{NanoSIMS isotope profile measurement}

The Cameca NanoSIMS 50L, housed at the Arizona State University, School of Molecular Science SIMS lab, was used to measure the Li isotope profiles across the core-rim boundaries/crystal interfaces, and over oscillatory and sector zones in zircons where $\mathrm{Li}$ gradients had been documented by ToF-SIMS imaging. Each line profile is composed of 20-40 spot analyses. For each spot analysis, a $\sim 200$ pA primary $\mathrm{O}^{-}$beam was used to pre-sputter the measurement site, and then a $\sim 80 \mathrm{pA}$ primary $\mathrm{O}^{-}$beam of $\sim 1 \mu \mathrm{m}$ diameter was used for acquisition. The total acquisition sputtering time for each spot analysis varied from 20 to $50 \mathrm{~min}$, depending on the overall Li concentration in the target. Under these conditions, the depth of excavation was $<1 \mu \mathrm{m}$. Ions of ${ }^{6} \mathrm{Li}^{+},{ }^{7} \mathrm{Li}^{+}$, ${ }^{30} \mathrm{Si}^{+}$and ${ }^{89} \mathrm{Y}^{+}$were collected by four detectors simultaneously during each analysis. Reproducibility on the Li isotope ratio measurement was evaluated by repeated analyses of ${ }^{7} \mathrm{Li} /{ }^{6} \mathrm{Li}$ in zircon M257 ( 0.86 ppm Li, Li et al., 2011) and a synthetic zircon ZLi-19 (tens to hundreds of $\mathrm{ppm} \mathrm{Li}$ ). The reproducibility was generally better than $3 \%$ at $1 \mathrm{SD}$ (Fig. 2).

\section{Results}

\subsection{ToF-SIMS imaging}

A key feature revealed by ToF-SIMS ion imaging is the sharp concentration gradients for $\mathrm{Li}$ in all of the zircons analyzed here (Figs. 3 and 4). These sharp chemical gradients appear to correlate with either core-rim structures (LB04-19-02, C88-29-7-6, DD81-32-6-8, DD96-4-5-11) or oscillatory zoning (DD86-25a-3-6) observed in CL images. These gradients record a factor of three or greater change in Li concentrations over 2 to $4 \mu \mathrm{m}$. Considering the blurring effect due to the beam size and counting statistics, the exact Li gradients could be even sharper in these zircons. Whole grain Li ion images are available in the Supplementary File 1.

\subsection{Li isotope profiles measured by NanoSIMS}

The four zircon grains measured by NanoSIMS display Li concentration gradients consistent with ToF-SIMS observations (Figs. 3 and 4). All of the analyzed zircons show 20-30\% Li isotopic variation within $\sim 50 \mu \mathrm{m}$ (Fig. 5). Characteristic diffusion-type gradients are documented in the "dips" seen across core-rim boundaries in the $\delta^{7} \mathrm{Li}$ profiles of zircon C88-29-7-6 and D81-32-6-8. Zircon D96-4-5-11 shows generally increasing $\delta^{7} \mathrm{Li}$ with increasing ${ }^{7} \mathrm{Li} /{ }^{30} \mathrm{Si}$ and ${ }^{7} \mathrm{Li} /{ }^{89} \mathrm{Y}$ ratios along the measured profile. Zircon DD86-25a-3-6 has a complicated $\delta^{7} \mathrm{Li}$ pattern across the region of oscillatory zoning. All data are provided in Supplementary File 2. 

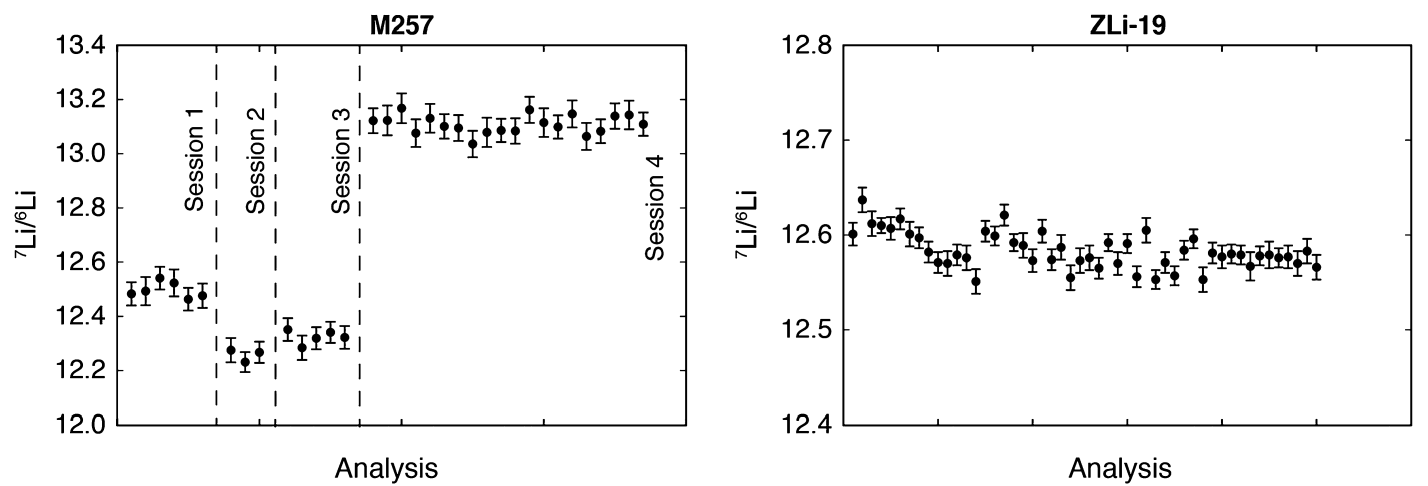

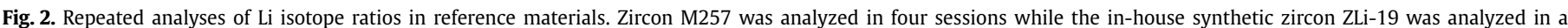

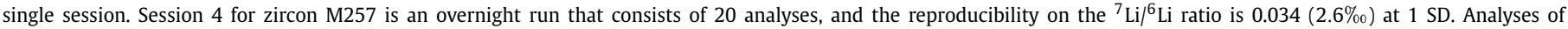

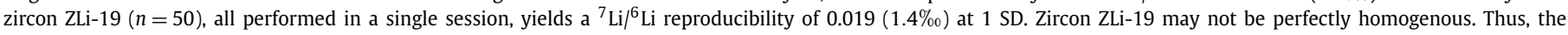
repeatability should reflect the maximum analytical uncertainty.
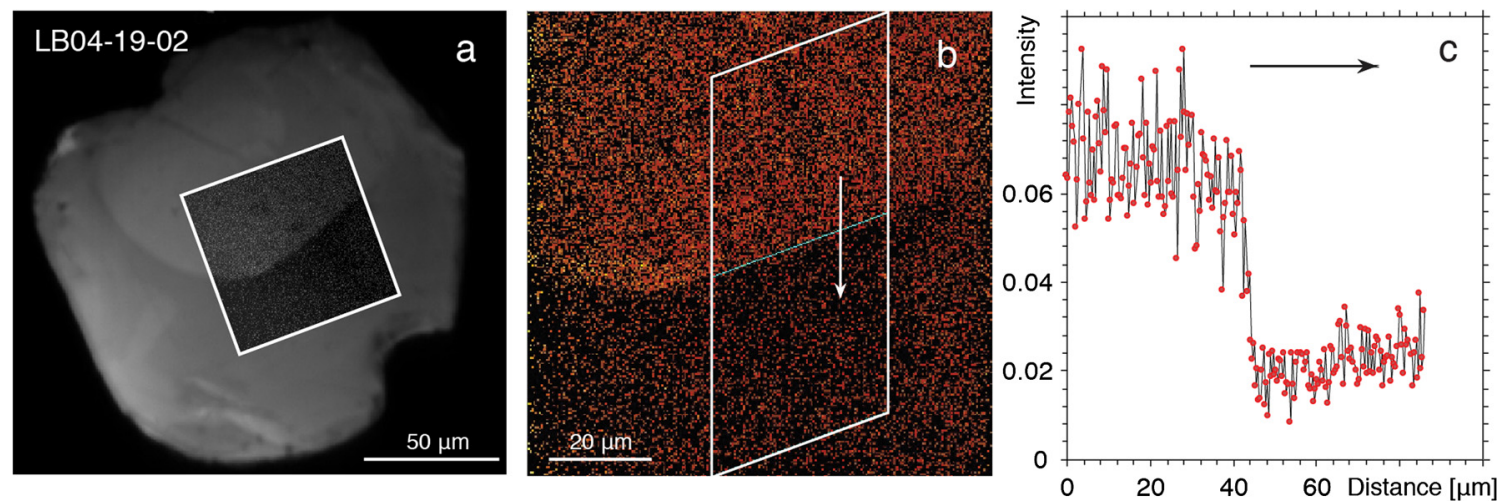

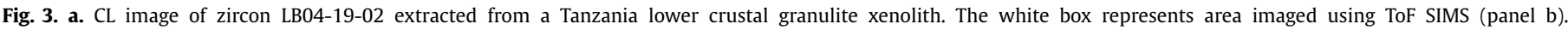

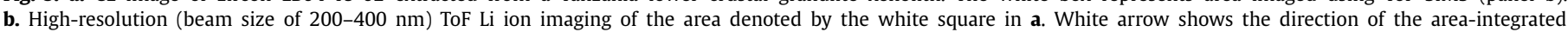
(marked by the white square in $\mathbf{b}){ }^{7} \mathrm{Li}$ intensity profile shown in $\mathbf{c} .{ }^{7} \mathrm{Li}$ intensity was normalized to the total ion count for every pixel.

Generally, low $\delta^{7} \mathrm{Li}$ values are associated with low Li concentrations in these zircons (Fig. 5), an observation that is consistent with diffusion driven Li isotope fractionation (e.g., Richter et al., 2003; Teng et al., 2006; Jeffcoate et al., 2007). However, the rim of zircon C88-29-7-6 presents a counterintuitive observation, where the $\delta^{7} \mathrm{Li}$ value decreases with increasing Li concentration. Note that the $\mathrm{Y}$ (and probably REE concentrations) concentration does not correlate with CL bands well (e.g., zircon DD86-25a-3-6) while Li concentration patterns seem to follow the CL bands (Fig. 4).

\section{Discussion}

The entire range of $\delta^{7} \mathrm{Li}$ of granitic rocks $(n=130)$ analyzed so far is $\sim 12 \%$ o (Teng et al., 2009), making it difficult to attribute the $20-30 \%$ single crystal $\delta^{7} \mathrm{Li}$ variations to changing compositions of the magma. Rather, such large $\delta^{7} \mathrm{Li}$ variations are similar to those seen in minerals from mantle xenoliths and phenocrysts in lavas, which reflect Li diffusion processes during melt-rock/mineral interaction (Jeffcoate et al., 2007; Parkinson et al., 2007; Rudnick and Ionov, 2007). We thus posit that the large Li isotopic fractionation in zircons results from diffusion.

\subsection{Sharp Li zoning in natural zircons}

The experimental studies of Cherniak and Watson (2010) and Trail et al. (2016) showed that Li diffusion is fast in zircon. However, if Li diffuses at the rate determined by Cherniak and Watson (2010) and Trail et al. (2016), the sharp Li concentration gradients would require extremely fast zircon growth rates and metamorphic events. Here we follow Trail et al. (2016) and use the midpoint slope $\left(S_{0}\right)$, which measures the sharpness of the gradient, to estimate the timescale of heating. We approximate $S_{0}$ using the distance (l) from $25 \%$ to $75 \%$ of the total concentration change:

$S_{0}=\frac{50 \%}{l}$

On the other hand, $S_{0}$ is a function of diffusivity $(D)$ and duration $(\Delta t)$ :

$S_{0}=\frac{28.21}{\sqrt{D \Delta t}}$

Equation (2) is from Trail et al. (2016). According to the Ti concentrations (Bouvier et al., 2012), the TTG and sanukitoid zircons likely crystallized at $700-800^{\circ} \mathrm{C}$. At this temperature, to preserve the sharp Li gradient, with $l$ of a couple of $\mu \mathrm{m}$, these TTG and sanukitoid zircons needed to crystallize within years to tens of years (Fig. 6). This translates into 1-10 $\mu \mathrm{m} / \mathrm{yr}$ growth rates at $700-800^{\circ} \mathrm{C}$, orders of magnitude faster than $\mathrm{Zr}$ diffusivity would allow in granitic systems (Watson, 1996; Zhang and Xu, 2016). Similarly, the step function Li gradient in the granulite zircon requires the same short timescales for the crystallization of zircon during the granulite facies metamorphism, which is unlikely. The widespread sharp Li concentration gradients in zircons suggest a much lower effective diffusivity for Li in natural zircons than experimentally determined (Cherniak and Watson, 2010; Trail et al., 2016), and this difference may result from multiple modes of Li diffusion in zircon. 

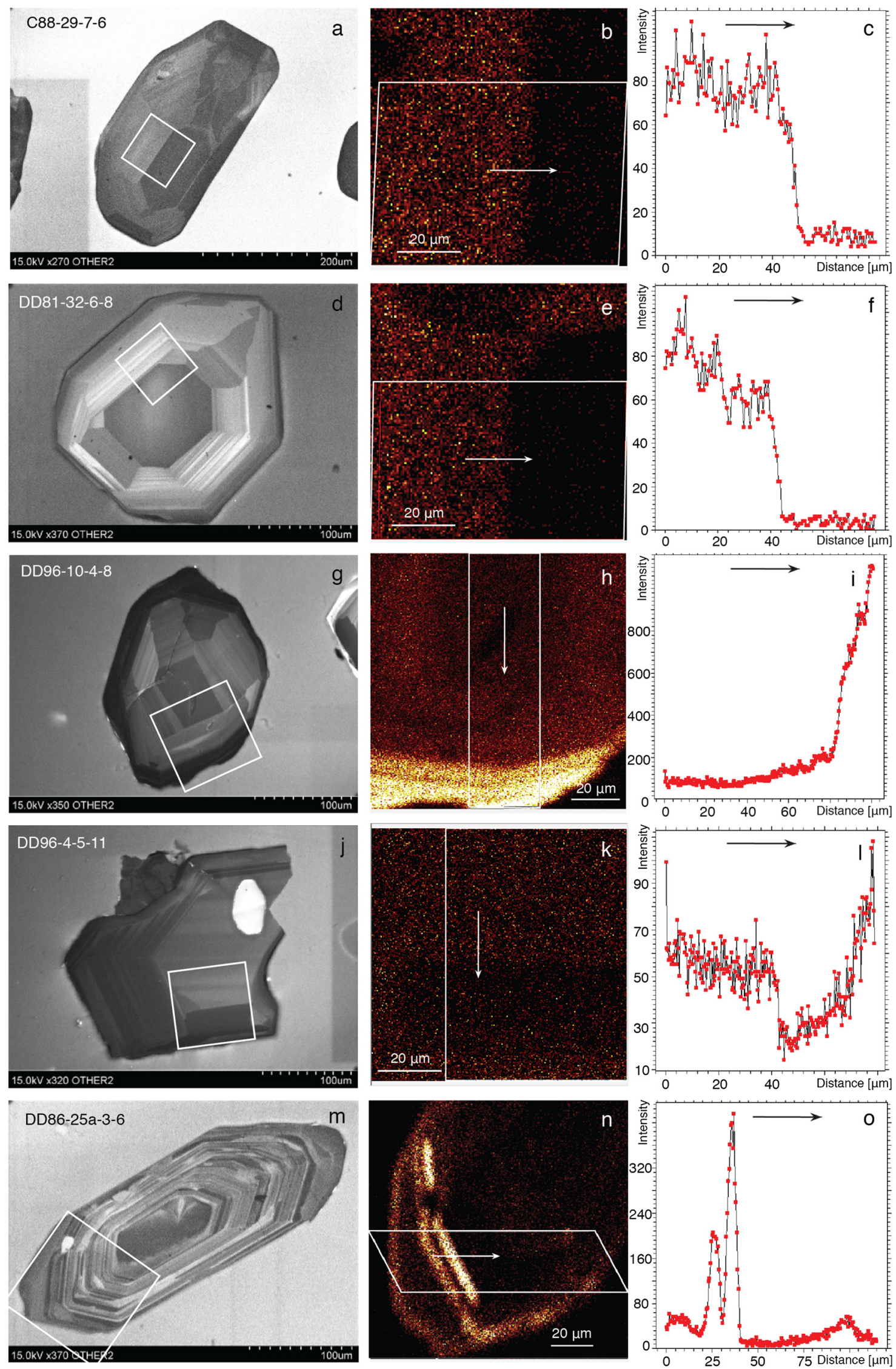

Fig. 4. Same figure configuration of images as in Fig. 3. CL images are from Bouvier et al. (2012). According to Bouvier et al. (2012), Li concentrations in these zircons from TTGs and sanukatoids range from 1 to $14 \mathrm{ppm}$, but the actual variation is probably larger, as suggested by our ion imaging. 

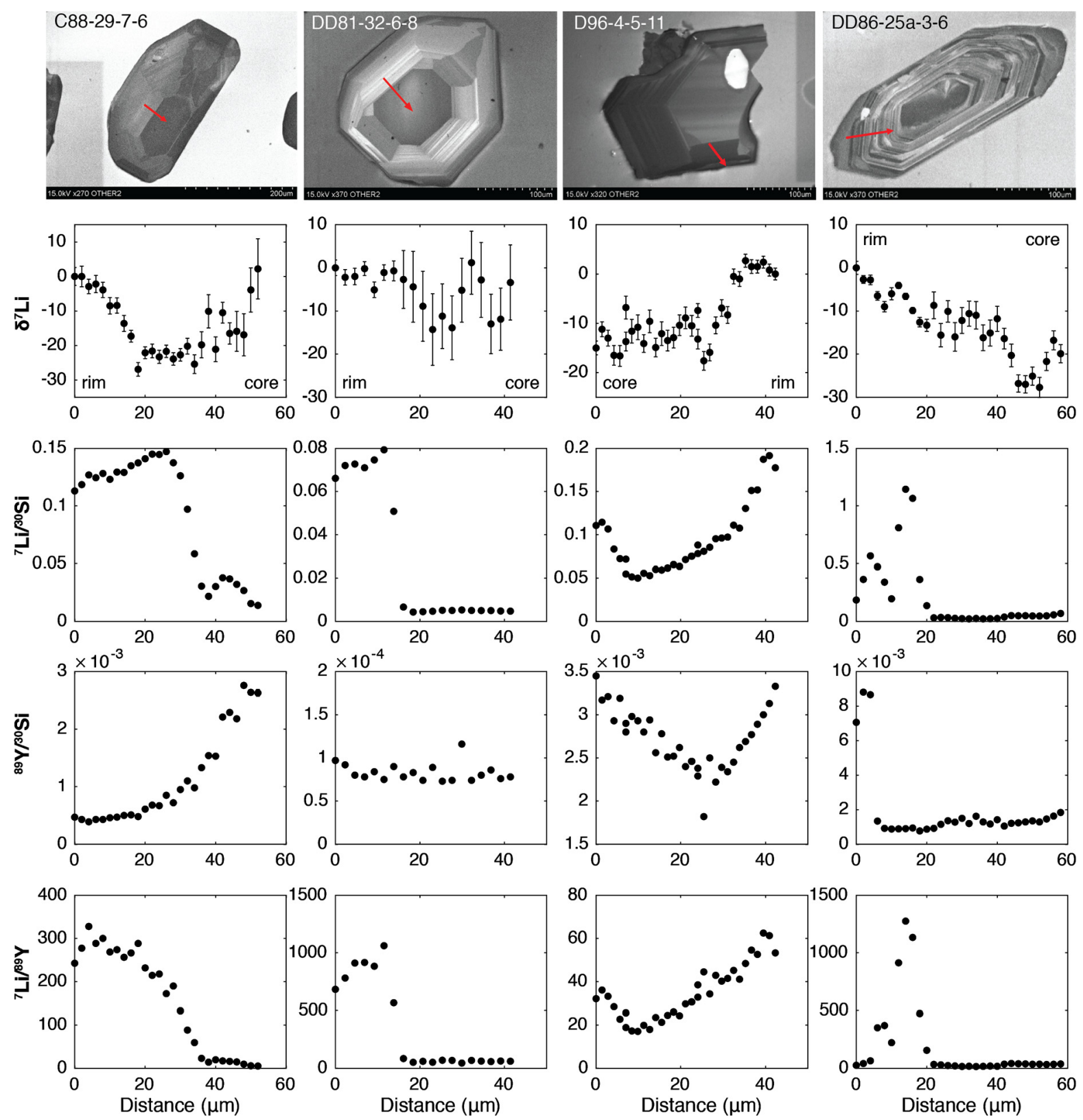

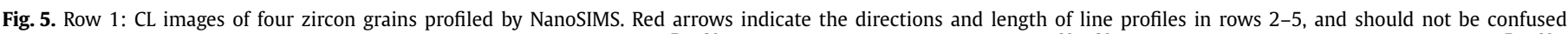

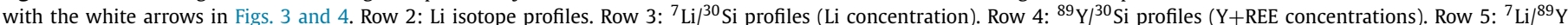

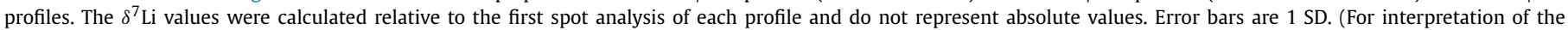
references to color in this figure legend, the reader is referred to the web version of this article.)

Two-mode Li diffusion has been observed in pyroxene (Richter et al., 2014) and olivine (Dohmen et al., 2010) in laboratory experiments. These authors found that Li may occupy both interstitial and metal sites in pyroxene. Although $\mathrm{Li}$ in the interstitial site diffuses orders of magnitude faster than Li in the metal site, Li favors the metal site over the interstitial site, and consequently, Li diffusion in pyroxene is limited by the available metal sites. This two-mode diffusion creates sharp concentration gradients that propagate as step functions (Dohmen et al., 2010; Richter et al., 2014). Ushikubo et al. (2008) and Bouvier et al. (2012) argued that Li may charge couple with REE and Y in a zircon lattice, and this charge coupling fixes Li ions in the zircon lattice because REE and Y do not diffuse significantly in zircon under crustal conditions. Consequently, Li diffusion in zircon will be similar to that in pyroxene, where some $\mathrm{Li}$ ions are coupled to $\mathrm{REE}+\mathrm{Y}$ and together they diffuse extremely slowly, while at the same time the rest of the Li ions diffuse faster, perhaps as fast as that determined by Cherniak and Watson (2010) and Trail et al. (2016).

Coupling with REE+Y has two obvious effects on Li diffusion in zircon. First, it reduces Li diffusivity significantly and increases the chance of preserving sharp concentration gradients formed during growth. Fig. 7 shows how the relaxation of a sharp Li concentration gradient changes as a function of the proportions of coupled and uncoupled Li $\left(L i_{R E E+Y} / L i_{\text {fast }}\right)$. Second, charge coupling with REE $+Y$ may promote the formation of sharp Li gradients through diffusion. Lithium diffuses to follow the REE $+Y$ gradients in zircon, even though a significant amount of Li may diffuse without coupling with REE $+\mathrm{Y}$. In the case where the REE $+\mathrm{Y}$ gradient is sharp, which may happen when the zircon grows in multiple stages, $\mathrm{Li}$ will diffuse to form similarly sharp gradients at equilibrium, as predicted by our two-mode diffusion model (Fig. 8 and Supple- 


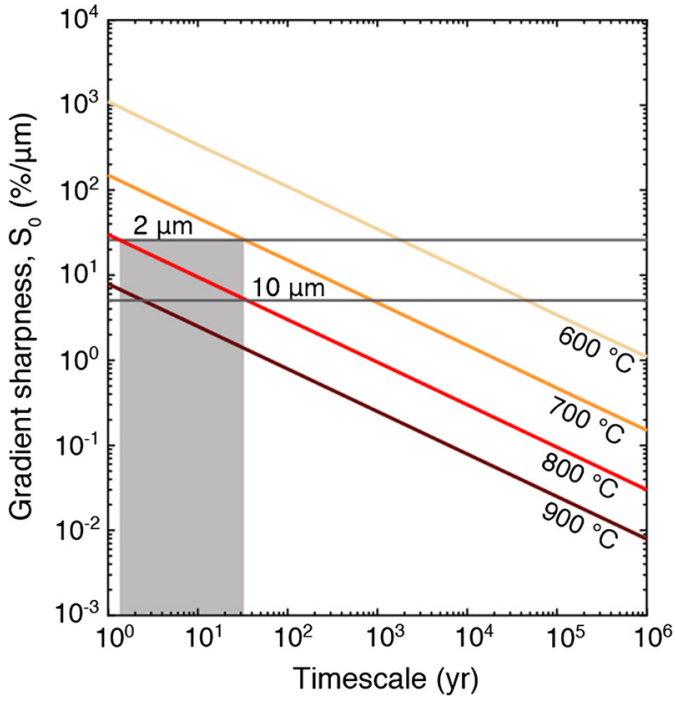

Fig. 6. Gradient sharpness, approximated by midpoint slope $\left(S_{0}\right)$, in a diffusion profile as a function of temperature and heating timescale. The horizontal gray lines mark the $S_{0}$ values corresponding to $l$ of 2 and $10 \mu \mathrm{m}$. The sharp Li gradients in the zircons studied here have $l$ of $\sim 2 \mu \mathrm{m}$. The gray band projects the range of heating timescales needed to preserve the observed sharp Li gradients using the Li diffusivity from Cherniak and Watson (2010) and Trail et al. (2016). The timescales derived using these experimentally determined diffusivities are much too short (less than or equal to $30 \mathrm{yrs}$ ) for zircon growth and metamorphism.

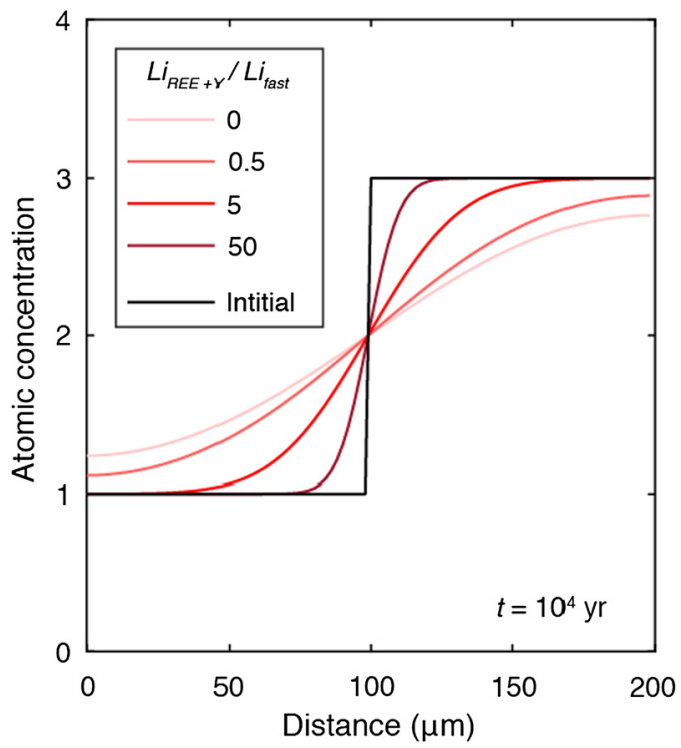

Fig. 7. One-dimensional model of relaxation of a sharp Li gradient in a $200 \mu \mathrm{m}$ closed system. Temperature is $750^{\circ} \mathrm{C}$, duration is $10^{4} \mathrm{yr}$ and a uniform REE atomic concentration of three was assumed. The ratio of REE coupled $\mathrm{Li}$ to uncoupled $\mathrm{Li}$ $\left(L i_{R E E+Y} / L i_{\text {fast }}\right)$ in the bulk system is determined by the concentration of REE coupling sites $\left(C_{R E E+Y}\right)$, non-REE sites $\left(C_{\text {fast }}\right.$, assumed to be $\left.10^{6}\right)$ and a site partitioning coefficient $k$ : $L i_{R E E+Y} / L i_{\text {fast }}=k^{*} C_{R E E+Y} / C_{\text {fast }}$ until all REE sites are saturated, then any extra Li diffuses in the fast mode. The site partition coefficient $k$ was varied to give the range of $L i_{R E E+Y} / L i_{\text {fast }}$. See section 6.2 for more details of the proposed two-mode diffusion model.

mentary File 3 ). In both cases, the REEs are assumed to be partially coupled with $\mathrm{Li}$ and the remaining Li enters other coupled substitution mechanisms in zircon. Lithium diffuses into the high REE zone (Fig. 8) and changes the REE substitution mechanism: Li + REE-X $=$ Li-REE $+\mathrm{X}$, where $\mathrm{X}$ is another $1+$ cation (e.g., $\mathrm{H}$ ). This exchange reaction basically fixes $\mathrm{Li}$ and releases $\mathrm{X}$ if the LiREE coupling mechanism is more stable than the X-REE coupling mechanism. A site partition coefficient, $k$, which determines Li partitioning between the REE-coupling and non-REE sites, together
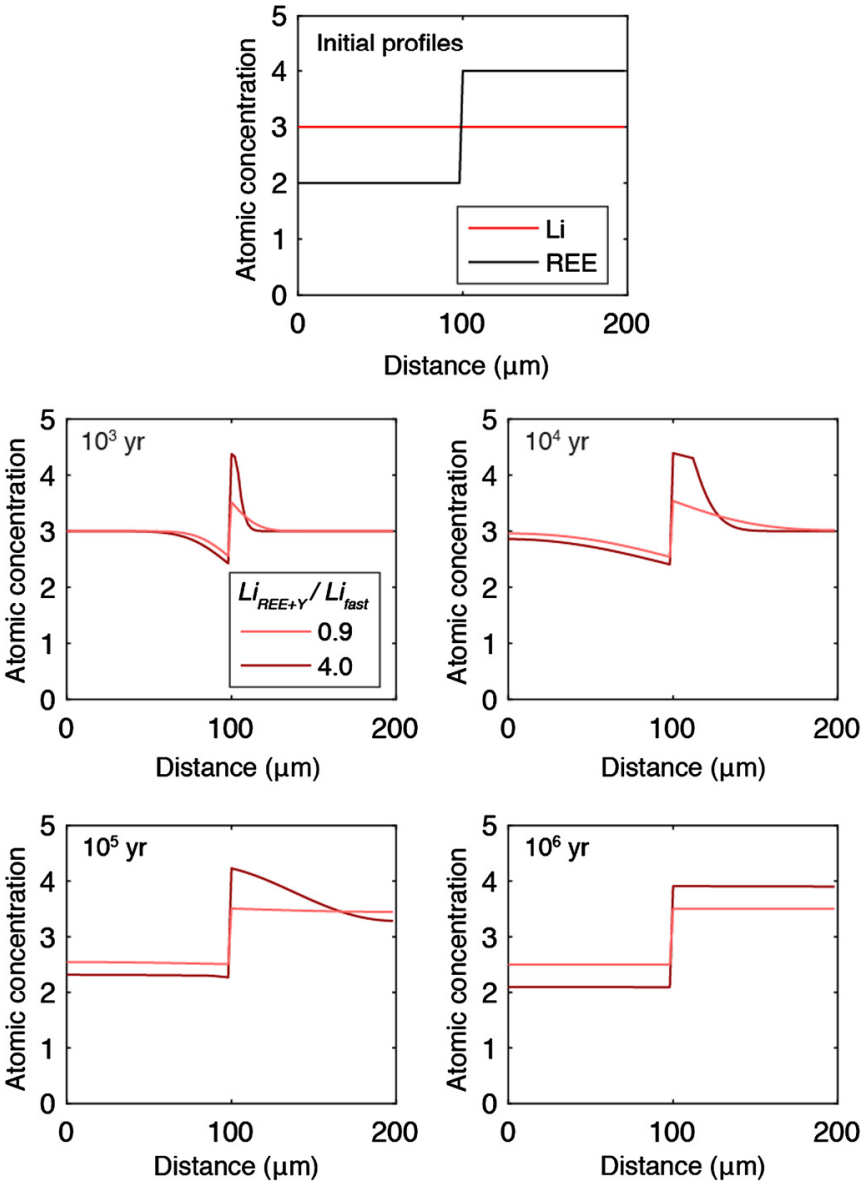

Fig. 8. One-dimensional Li diffusion model in a $200 \mu \mathrm{m}$ closed system with a step function REE gradient. The initial Li concentration profile is uniform. Temperature is $750^{\circ} \mathrm{C}$. Li diffuses to form a step function profile that mimics the REE profile. The proportion of $\mathrm{Li}$ coupled to the $\mathrm{REE}+\mathrm{Y}\left(\mathrm{Li}_{\mathrm{REE}+\mathrm{Y}}\right)$ in the system controls the Li concentration difference between the two steps at equilibrium and is quantified using $L i_{R E E+Y} / L i_{\text {fast }}$. The values for this ratio, noted in the legends are, initial values for the bulk system, and they approach 1 and 10 , for $L i_{R E E+Y} / L i_{\text {fast }}=0.9$ and 4.0 , respectively, at equilibrium. This differs from the scenario in Fig. 7, which has a uniform REE concentration gradient and thus constant $L i_{R E E+Y} / L i_{\text {fast }}$. The simulation video in Supplementary File 3 shows the evolution of the Li concentration profile through $5 \times 10^{5}$ yrs assuming an initial $L i_{R E E+Y} / L i_{\text {fast }}$ of 4.0 .

with the numbers of these two sites, gives the relative proportions of $\mathrm{Li}$ in the two diffusion modes $L i_{R E E+Y} / L i_{\text {fast }}$, where the subscript fast indicates $\mathrm{Li}$ in the fast diffusion mode.

The sharp Li gradients in our zircons are generally correlated with zoning structures in CL, which presumably formed during crystallization. Meanwhile, sharp Y gradients are generally absent. We suggest that the sharp Li gradients formed during crystal growth due to e.g., changing melt composition, and their subsequent relaxation was sluggish because much of the Li was locked by REE and Y, or there is an abrupt change in REE and Y substitution mechanism across the CL structure boundaries which may not be reflected in REE or Y concentrations. On the other hand, the decreasing $\delta^{7} \mathrm{Li}$ across the Li gradients suggests that some Li ions must have substituted in zircon by fast diffusion mechanisms.

\subsection{Modeling Li diffusion in zircon C88-29-7-6}

Direct evidence for multiple diffusion modes comes from the counterintuitive observation of the negatively correlated Li isotope and concentration profiles found in the rim of zircon C88-29-7-6 (Fig. 5). The decreasing $\delta^{7} \mathrm{Li}$ value in the direction of increasing $\mathrm{Li}$ concentration (as measured by ${ }^{7} \mathrm{Li} /{ }^{30} \mathrm{Si}$ ) suggests Li diffuses from 
the low concentration outer part of the rim to the high concentration inner part of the rim, similar to an uphill diffusion mechanism (e.g., Zhang, 1993). Although Li concentration increases, Y concentration increases even faster, and the $\mathrm{Li} / \mathrm{Y}$ ratio decreases from the outer part to the inner part of the rim (Fig. 5). Assuming Y concentration is proportional to $\mathrm{REE}+\mathrm{Y}$ concentration, this counterintuitive diffusion profile can be explained if Li charge couples with REE + Y. Here we modeled Li diffusion during growth of zircon C88-29-7-6 with the following assumptions:

(1) $\mathrm{REE}+\mathrm{Y}$ couples with some fraction of $\mathrm{Li}$ and this coupled $\mathrm{Li}$ has a diffusivity of 0 , whereas the rest of the Li diffuses at the rate determined by Cherniak and Watson (2010) and Trail et al. (2016);

(2) The zircon is spherical and grows from $6 \mu \mathrm{m}$ to $60 \mu \mathrm{m}$ at a constant radial growth rate;

(3) Li concentration in the zircon boundary changes abruptly at the midpoint of growth (radius reaching $33 \mu \mathrm{m}$ );

(4) Temperature is $750^{\circ} \mathrm{C}$ and constant during zircon growth.

(5) ${ }^{6} \mathrm{Li}$ diffuses $3 \%$ faster than ${ }^{7} \mathrm{Li}$. The kinetic fractionation factor for Li isotopes in zircon is yet to be determined, but ${ }^{6} \mathrm{Li}$ was generally found to diffuse $2-4 \%$ faster than ${ }^{7} \mathrm{Li}$ in silicate melt (Richter et al., 2003) and silicate minerals (Parkinson et al., 2007; Richter et al., 2014).

Diffusion of Li isotopes that are not coupled with REE+Y is described by Fick's 2nd law:

$\frac{\partial C_{j}^{f}}{\partial t}=D_{j}\left(\frac{\partial^{2} C_{j}^{f}}{\partial r^{2}}+\frac{2}{r} \frac{\partial C_{j}^{f}}{\partial r}\right), \quad 0 \leq r \leq\left. R\right|_{t}$

where $C$, hereafter, is atomic concentration; the superscript $f$ indicates fast diffusing Li that is not coupled with REE+Y, the subscript $j$ denotes the diffusing species i.e., ${ }^{6} \mathrm{Li}$ and ${ }^{7} \mathrm{Li}$. $R$ is the instant crystal radius and $r$ is the distance to the center. Initial and boundary conditions are:

$\left.\frac{\partial C_{j}}{\partial r}\right|_{t=0}=0, \quad 0 \leq r \leq\left. R\right|_{t}$
$\left.\frac{\partial C_{j}}{\partial r}\right|_{r=0, t}=0$,

$\left.\frac{C_{7}}{C_{6}}\right|_{t=0, r}=12.2$

$\left.\frac{C_{7}}{C_{6}}\right|_{r=R, t}=12.2$

where the subscripts 6 and 7 denote the isotopes ${ }^{6} \mathrm{Li}$ and ${ }^{7} \mathrm{Li}$, respectively. According to assumption (2):

$\frac{d R}{d t}=\frac{R_{f}-R_{i}}{\tau}$

where $R_{i}$ and $R_{f}$ are the initial and final zircon radius, respectively; $\tau$ is the timescale of growth. To mimic the measured $\mathrm{Li} / \mathrm{Si}$ profile, we let the total Li concentration in the zircon boundary layer increase abruptly by a factor of six at $t=0.5 \tau$ :

$\left.C_{L i}\right|_{r=R, 0<t \leq 0.5 \tau}=0.5$;

$\left.C_{L i}\right|_{r=R, 0.5 \tau<t \leq \tau}=3$;

$\mathrm{REE}+\mathrm{Y}$ concentration is given by:

$\left.C_{R E E+Y}\right|_{t=0, r}=9$;

$\left.C_{R E E+Y}\right|_{r=R, t}=9-7.5 \frac{t}{\tau}$;
The concentrations of REE $+\mathrm{Y}$ coupled and vacancy coupled $\mathrm{Li}$ is a function of the concentrations of REE $+Y\left(C_{R E E+Y}\right)$ and the non-REE $\left(C_{\text {fast }}\right)$ sites, and a site partition coefficient, $k$, that determines the proportions of $\mathrm{Li}$ in the two sites:

$\left.\frac{C_{L i}^{R E E+Y}}{C_{L i}^{f a s t}}\right|_{r, t}=\left.k \frac{C_{R E E+Y}}{C_{f a s t}}\right|_{r, t}$
$\left.C_{L i}^{R E E+Y}\right|_{r, t} \leq\left. C_{R E E+Y}\right|_{r, t}$

Here we set $C_{\text {fast }}$ to be a constant $=5 \times 10^{5}$. This number is not important but the ratio of $C_{R E E+Y} / C_{\text {fast }}$ is. Like other partition coefficients, $k$ is a thermodynamic parameter and its relationship with temperature, pressure and matrix composition can potentially be determined by experiments. When $k$ is large, Li prefers the REE $+\mathrm{Y}$ coupling site. Equations (3)-(10) were solved numerically in 1000 time steps with a constant grid size of 100 for spherical zircon.

Fig. 9 shows two calculated diffusion profiles assuming $k=$ $6 \times 10^{6}$ and $10^{20}$, respectively. The total growth time is $15,000 \mathrm{y}$. A growth-diffusion simulation video for this zircon is available in Supplementary File 4 . This modeling exercise is compromised by the uncertainties in many parameters including growth rate, thermal history, change in melt composition, lattice vacancies/defects, etc., and it is not our intention to reconstruct the exact crystallization and diffusion history of this zircon. But by way of an example, the uphill diffusion and sharp concentration boundary can be produced at the same time if part of the Li couples with REE $+Y$ in zircon. Meanwhile, the wide diffusion trough in the $\delta^{7} \mathrm{Li}$ profile requires the existence of a small amount of fast diffusing $\mathrm{Li}$ in the lattice because complete coupling $(k \sim \infty)$ will create a sharp diffusion dip (as approximated by the $k=10^{20}$ model in Fig. 9), independent of other parameters in the model. In this model, we considered two diffusion modes for Li i.e., Li coupled with REE+Y and Li not coupled with REE+Y. This latter mode may be a combination of multiple modes depending on the coupling mechanisms and/or the distribution of vacancies/defects as Li diffuses in the zircon lattice. We used the diffusion coefficient determined by Cherniak and Watson (2010) and Trail et al. (2016) to approximate the average diffusivity for $\mathrm{Li}$ in these various diffusion modes that do not involve coupling with REE $+\mathrm{Y}$.

We suggest two possibilities for why this coupling effect on $\mathrm{Li}$ diffusion has not been observed in experimental studies. First, Li may not have charge coupled with REE in the experiments of Trail et al. (2016). The charge coupling between $\mathrm{Li}$ and REE $+\mathrm{Y}$ during Li diffusion depends on the substitution mechanisms of REE $+Y$ in the zircon lattice (Table 1), and this may not happen if the coupling between $\mathrm{Li}$ and $\mathrm{REE}+\mathrm{Y}$ results in a less stable REE and $\mathrm{Y}$ substitution mechanism in the zircon lattice. This translates into a composition-dependent multi-mode diffusion mechanism for $\mathrm{Li}$ in zircon. In this case, we speculate that Li may not couple with REE and $\mathrm{Y}$ in the xenotime-type substitution mechanism because this process will require an extra $\mathrm{Si}$, and $\mathrm{P}^{5+}$ is not mobile in zircon. Alternatively, Li could substitute for $\mathrm{H}$, which may be more mobile due to its smaller ionic radius as compared to Li. Although REE and Y may be incorporated in zircon primarily in a xenotimetype substitution $\left((\mathrm{Y}+\mathrm{REE})^{3+}+\mathrm{P}^{5+}=\mathrm{Zr}^{4+}+\mathrm{Si}^{4+}\right)$, there are only a few ppm or less $\mathrm{Li}$ in most natural zircons, which requires less than a few tens of ppm REE for charge coupling. Any change in the trace element composition may affect the $\mathrm{Li}$ and $\mathrm{REE}+\mathrm{Y}$ coupling and thus the modes of Li diffusion in zircon. Second, Li may diffuse through interconnected REE coupling sites in Trail et al.'s experiments. The REE-doped zircons used by Trail et al. (2016) have at least 10 times higher REE concentrations than most natural zircons. At very high concentrations, REE and $\mathrm{Y}$ may form interconnected paths in the zircon lattice, and Li ions that are charge 

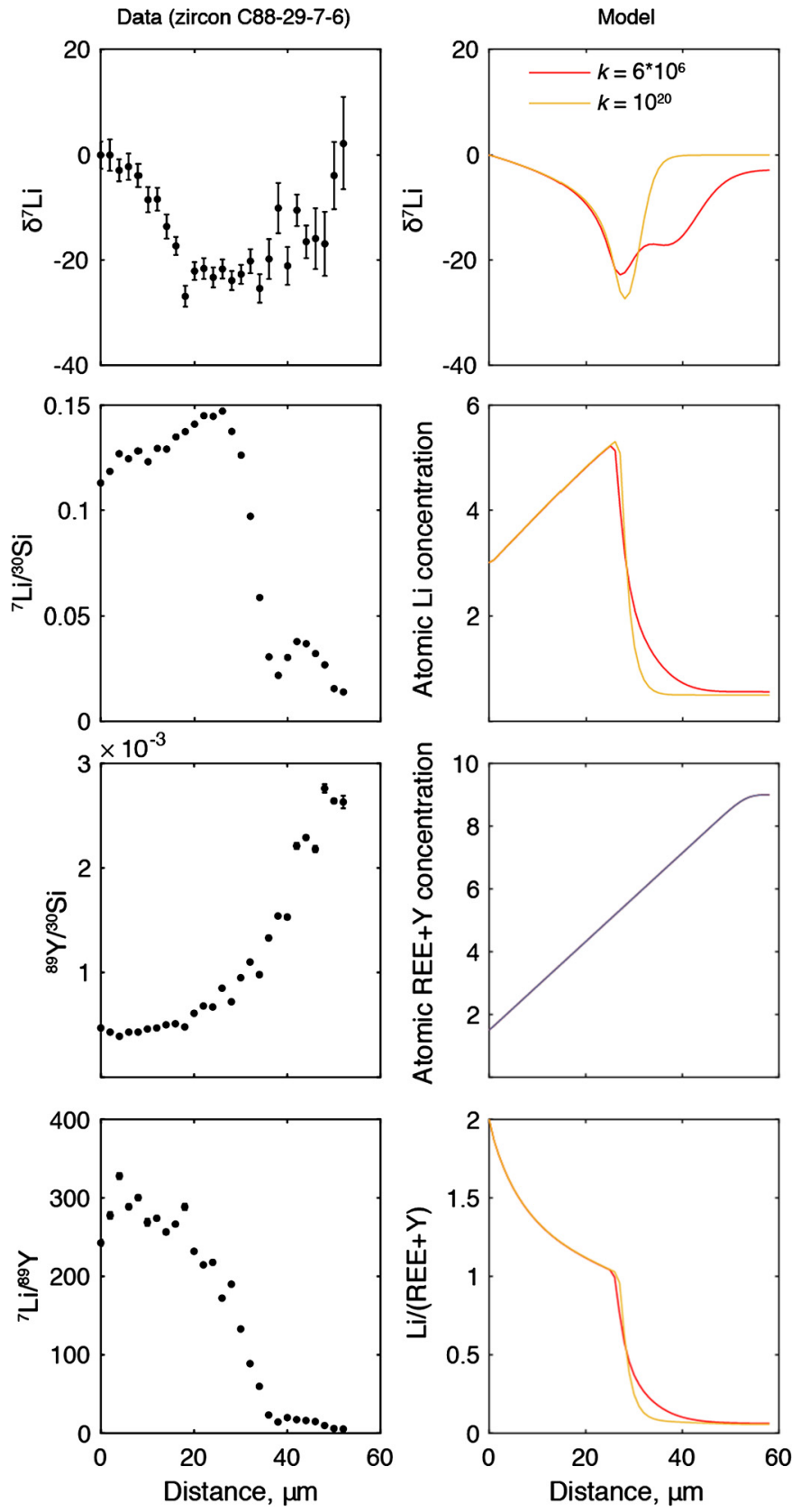

Fig. 9. Comparison between modeled and measured profiles in zircon C88-29-7-6 An intermediate $k=6 \times 10^{6}$, given other assumptions, produces the isotope and element profiles that best match the data. A $k=10^{20}$ was used to approximate the situation when Li couples with REE $+\mathrm{Y}$ completely until all REE $+\mathrm{Y}$ coupling sites are saturated.

coupled with REE+Y may diffuse in these paths without changing the bulk REE $+\mathrm{Y}$ substitution mechanism. In this case, Li, though charge coupled with REE $+\mathrm{Y}$, may diffuse rapidly.

What is the substitution mechanism of Li that diffuses in the fast mode? This question can be generalized to all interstitial impurity elements in any crystals, including $\mathrm{Li}$ in olivine and pyroxene, whose diffusion behavior has been experimentally studied (Dohmen et al., 2010; Richter et al., 2014). Using Li in zircon again as an example, if fast interstitial diffusion of $\mathrm{Li}$ is not coupled with any other ions, local charge balance will not be maintained as $\mathrm{Li}$ diffuses; if the fast interstitial diffusion of Li couples with elements in the metal site, its diffusivity will be dictated by the metal site elements, which diffuse by a slow vacancy mechanism. It has been suggested that Li may couple with itself, with three Li ions in the interstitial sites surrounding one $\mathrm{Li}$ ion in the $\mathrm{Zr}$ site (Bouvier et al., 2012). How rapidly metal site Li diffuses in zircon is not clear. Lithium can also diffuse rapidly by exchanging with other univalent impurity elements, but the concentrations of univalent elements are generally too low (ppm level) to form an "exchange network" in natural zircons. On the other hand, univalent cations larger than $\mathrm{Li}(\mathrm{Na}, \mathrm{K}, \mathrm{Rb}, \mathrm{Cs})$ are probably too large to fit in the interstitial site. Another possibility is to put four Li ions in the interstitial sites surrounding a vacancy in the $\mathrm{Zr}$ site (Bouvier et al., 2012). Because the vacancy diffuses rapidly, Li using this substitution mechanism may also diffuse rapidly. At present, we are unable to reach a conclusive answer to these matters and recommend further work, particularly additional experimental studies.

Another interesting question is what causes the zoning structures in zircon $\mathrm{CL}$ images. It has been suggested that zircon $\mathrm{CL}$ zonings are correlated with REE compositions, especially Dy (e.g., Koschek, 1993). However, our micron-scale Y profiles do not support this hypothesis. Yttrium is not a REE, but it is geochemically similar to REE, and Y concentration well correlates with REE concentrations in zircon (e.g., De Hoog et al., 2014). Cathodoluminescence microscopy characterization is important in zircon geochronology and other in situ isotope studies, and we suggest future work on the origin of zircon CL structures.

\subsection{Implications for Li-in-zircon geospeedometry}

Li-in-zircon geospeedometry has potential applications in constraining the timescales of zircon crystallization, metamorphic heating events, or any geological process in which zircon participates (e.g., changing magmatic temperatures). Using experimentally determined Li diffusivity in zircon, it has been argued that the sharp Li concentration gradients seen in some Hadean zircons from Jack Hills, Australia constrain the temperature of any post-crystallization heating event to be below $500^{\circ} \mathrm{C}$, lower than the Curie temperature of magnetite at $585^{\circ} \mathrm{C}$ (Trail et al., 2016). Therefore, the magnetite inclusions in some of the Jack Hills zircons may record the original magnetic field in the Hadean (Trail et al., 2016). However, we have documented here that sharp gradients in Li concentrations, which are commonly seen in igneous zircons that crystallized in granitic magmas at $700-800^{\circ} \mathrm{C}$, can survive granulite facies metamorphism in the lower crust. Multi-mode Li diffusion propagates in step functions (Dohmen et al., 2010; Richter et al., 2014), and the sharp gradients in Li concentrations in natural zircons is not an indicator of low temperatures (e.g., below the Curie point of magnetite). Coupling between $\mathrm{Li}$ and $\mathrm{REE}+\mathrm{Y}$ also makes a Li concentration profile unsuitable for predicting the tendency and direction of diffusion. Li-in-zircon may become a potentially useful geospeedometer if the distribution of $\mathrm{Li}$ in various diffusion modes in zircon can be determined as a function of temperature, pressure and trace element composition in the zircon.

\section{Conclusions}

ToF-SIMS ion imaging and NanoSIMS Li isotope profiling reveal the mechanism(s) of Li diffusion in zircon. Sharp Li concentration gradients and massive Li isotopic fractionation (20-30\%) in individual crystals are commonly seen in natural zircons. We attribute the large isotopic variation to Li diffusion that was "frozen" in zircons, thus, Li isotopes in zircons may not be used to infer the compositions of the magma source materials.

Preservation of sharp Li concentration gradients in igneous and granulite facies zircons requires a much lower effective Li diffusivity than that determined experimentally, suggesting multiple Li diffusion modes in natural zircons. Multi-mode Li diffusion may involve charge coupling with REE and Y, which is supported by Li diffusion in the direction of decreasing $\mathrm{Li} / \mathrm{Y}$ ratio but increasing 
Li concentration, as observed in zircon C88-29-7-6. Our modeling suggests that the coupling between $\mathrm{Li}$ and $\mathrm{REE}+\mathrm{Y}$ is not the only way that Li diffuses, and a significant amount of Li may diffuse in the fast mode(s).

Our results demonstrate that sharp concentration gradients of $\mathrm{Li}$ within zircon can exist despite significant Li diffusion. The mechanism of Li diffusion in zircon needs to be fully understood before Li-in-zircon geospeedometry can be applied to natural systems with confidence. In particular, detailed studies are required to delineate the factors that control the substitution mechanisms of REE and $\mathrm{Y}$ and thus may affect Li partitioning in different diffusion modes in zircon.

\section{Acknowledgements}

This project was supported by NSF grants EAR 0948549 and 1551388 (to RLR and WFM), a UMD research grant to RLR, and a University of Maryland Wylie Fellowship to M.T. Special thanks to Dustin Trail for insightful discussions, John Valley for providing the natural zircon samples, and Xian-Hua Li for loaning the zircon standard M257 to us for three years. We appreciate discussions with John Valley, Daniele Cherniak, Glenn Gaetani, Richard Hervig, Lynda Williams and Benjamin Weiss. We thank Youxue Zhang for his insightful review comments and editor An Yin for his efficient handling. M.B. is grateful for NASA grant NNX15AD94G (PI Danial Apai) and NSF grant EAR-1352996 (PI Richard Hervig) that supported her during this work.

\section{Appendix A. Supplementary material}

Supplementary material related to this article can be found online at http://dx.doi.org/10.1016/j.epsl.2017.06.034.

\section{References}

Bellucci, J.J., McDonough, W.F., Rudnick, R.L., 2011. Thermal history and origin of the Tanzanian Craton from $\mathrm{Pb}$ isotope thermochronology of feldspars from lower crustal xenoliths. Earth Planet. Sci. Lett. 301, 493-501.

Bouvier, A.-S., Ushikubo, T., Kita, N., Cavosie, A., Kozdon, R., Valley, J., 2012. isotopes and trace elements as a petrogenetic tracer in zircon: insights from Archean TTGs and sanukitoids. Contrib. Mineral. Petrol. 163, 745-768.

Chan, L.H., Edmond, J.M., Thompson, G., Gillis, K., 1992. Lithium isotopic composition of submarine basalts: implications for the lithium cycle in the oceans. Earth Planet. Sci. Lett. 108, 151-160.

Cherniak, D.J., Watson, E.B., 2010. Li diffusion in zircon. Contrib. Mineral. Petrol. 160, 383-390.

De Hoog, J.C.M., Lissenberg, C.J., Brooker, R.A., Hinton, R., Trail, D., Hellebrand, E., 2014. Hydrogen incorporation and charge balance in natural zircon. Geochim. Cosmochim. Acta 141, 472-486.

Dellinger, M., Bouchez, J., Gaillardet, J., Faure, L., Moureau, J., 2017. Tracing weathering regimes using the lithium isotope composition of detrital sediments. Geology 45 (5), 411-414.

Dohmen, R., Kasemann, S.A., Coogan, L., Chakraborty, S., 2010. Diffusion of Li in olivine. Part I: experimental observations and a multi species diffusion model. Geochim. Cosmochim. Acta 74, 274-292.

Finch, R.J., Hanchar, J.M., Hoskin, P.W., Burns, P.C., 2001. Rare-earth elements in synthetic zircon: Part 2. A single-crystal X-ray study of xenotime substitution. Am. Mineral. 86, 681-689.

Gao, Y.-Y., Li, X.-H., Griffin, W.L., Tang, Y.-J., Pearson, N.J., Liu, Y., Chu, M.-F., Li, Q.-L., Tang, G.-Q., O'Reilly, S.Y., 2015. Extreme lithium isotopic fractionation in three zircon standards (Plešovice, Qinghu and Temora). Sci. Rep. 5.

Hanchar, J.M., Finch, R.J., Hoskin, P.W., Watson, E.B., Cherniak, D.J., Mariano, A.N. 2001. Rare earth elements in synthetic zircon: Part 1. Synthesis, and rare earth element and phosphorus doping. Am. Mineral. 86, 667-680.

Hoskin, P.W., Kinny, P.D., Wyborn, D., Chappell, B.W., 2000. Identifying accessory mineral saturation during differentiation in granitoid magmas: an integrated approach. J. Petrol. 41, 1365-1396.

Jeffcoate, A.B., Elliott, T., Kasemann, S.A., Ionov, D., Cooper, K., Brooker, R., 2007. Li isotope fractionation in peridotites and mafic melts. Geochim. Cosmochim. Acta 71, 202-218.

Koschek, G., 1993. Origin and significance of the SEM cathodoluminescence from zircon. J. Microsc. 171, 223-232.
Li, X.-H., Li, Q.-L., Liu, Y., Tang, G.-Q., 2011. Further characterization of M257 zircon standard: a working reference for SIMS analysis of Li isotopes. J. Anal. At. Spectrom. 26, 352-358.

Liu, X.-M., Rudnick, R.L., McDonough, W.F., Cummings, M.L., 2013. Influence of chemical weathering on the composition of the continental crust: insights from $\mathrm{Li}$ and $\mathrm{Nd}$ isotopes in bauxite profiles developed on Columbia River Basalts. Geochim. Cosmochim. Acta 115, 73-91.

Lundstrom, C.C., Chaussidon, M., Hsui, A.T., Kelemen, P., Zimmerman, M., 2005. Observations of $\mathrm{Li}$ isotopic variations in the Trinity Ophiolite: evidence for isotopic fractionation by diffusion during mantle melting. Geochim. Cosmochim. Acta 69, 735-751.

Mansur, A.T., Manya, S., Timpa, S., Rudnick, R.L., 2014. Granulite-facies xenoliths in rift basalts of northern Tanzania: age, composition and origin of Archean lower crust. J. Petrol. 55, 1243-1286.

Marks, M.A.W., Rudnick, R.L., McCammon, C., Vennemann, T., Markl, G., 2007. Arrested kinetic $\mathrm{Li}$ isotope fractionation at the margin of the Ilímaussaq complex, South Greenland: evidence for open-system processes during final cooling of peralkaline igneous rocks. Chem. Geol. 246, 207-230.

Marschall, H.R., Pogge von Strandmann, P.A.E., Seitz, H.-M., Elliott, T., Niu, Y., 2007. The lithium isotopic composition of orogenic eclogites and deep subducted slabs. Earth Planet. Sci. Lett. 262, 563-580.

Parkinson, I.J., Hammond, S.J., James, R.H., Rogers, N.W., 2007. High-temperature lithium isotope fractionation: insights from lithium isotope diffusion in magmatic systems. Earth Planet. Sci. Lett. 257, 609-621.

Penniston-Dorland, S., Liu, X.-M., Rudnick, R.L., 2017. Lithium isotope geochemistry. Rev. Mineral. Geochem. 82, 165-217.

Pistiner, J.S., Henderson, G.M., 2003. Lithium-isotope fractionation during continental weathering processes. Earth Planet. Sci. Lett. 214, 327-339.

Qiu, L., Rudnick, R.L., Ague, J.J., McDonough, W.F., 2011a. A lithium isotopic study of sub-greenschist to greenschist facies metamorphism in an accretionary prism, New Zealand. Earth Planet. Sci. Lett. 301, 213-221.

Qiu, L., Rudnick, R.L., McDonough, W.F., Bea, F., 2011b. The behavior of lithium in amphibolite- to granulite-facies rocks of the Ivrea-Verbano Zone, NW Italy. Chem. Geol. 289, 76-85.

Qiu, L., Rudnick, R.L., McDonough, W.F., Merriman, R.J., 2009. Li and $\delta^{7} \mathrm{Li}$ in mudrocks from the British Caledonides: metamorphism and source influences. Geochim. Cosmochim. Acta 73, 7325-7340.

Richter, F.M. Davis, A.M., DePaolo, D.J., Watson, E.B., 2003. Isotope fractionation by chemical diffusion between molten basalt and rhyolite. Geochim. Cosmochim. Acta 67, 3905-3923.

Richter, F., Watson, B., Chaussidon, M., Mendybaev, R., Ruscitto, D., 2014. Lithium isotope fractionation by diffusion in minerals. Part 1: pyroxenes. Geochim. Cosmochim. Acta 126, 352-370.

Rudnick, R.L., Ionov, D.A., 2007. Lithium elemental and isotopic disequilibrium in minerals from peridotite xenoliths from far-east Russia: product of recent melt/fluid-rock reaction. Earth Planet. Sci. Lett. 256, 278-293.

Rudnick, R.L., Tomascak, P.B., Njo, H.B., Gardner, L.R., 2004. Extreme lithium isotopic fractionation during continental weathering revealed in saprolites from South Carolina. Chem. Geol. 212, 45-57.

Speer, J.A., 1982. Zircon. In: Orthosilicates. In: Rev. Min., vol. 5, pp. 67-112.

Teng, F.-Z., McDonough, W.F., Rudnick, R.L., Walker, R.J., 2006. Diffusion-driven extreme lithium isotopic fractionation in country rocks of the Tin Mountain pegmatite. Earth Planet. Sci. Lett. 243, 701-710.

Teng, F.-Z., McDonough, W.F., Rudnick, R.L., Wing, B.A., 2007. Limited lithium isotopic fractionation during progressive metamorphic dehydration in metapelites: a case study from the Onawa contact aureole, Maine. Chem. Geol. 239, 1-12.

Teng, F.-Z., Rudnick, R.L., McDonough, W.F., Wu, F.-Y., 2009. Lithium isotopic systematics of A-type granites and their mafic enclaves: further constraints on the Li isotopic composition of the continental crust. Chem. Geol. 262, 370-379.

Tomascak, P.B., Magna, T., Dohmen, R., 2016. Advances in Lithium Isotope Geochemistry. Springer International Publishing.

Tomascak, P.B., Tera, F., Helz, R.T., Walker, R.J., 1999. The absence of lithium isotope fractionation during basalt differentiation: new measurements by multicollector sector ICP-MS. Geochim. Cosmochim. Acta 63, 907-910.

Trail, D., Cherniak, D.J., Watson, E.B., Harrison, T.M., Weiss, B.P., Szumila, I., 2016. Li zoning in zircon as a potential geospeedometer and peak temperature indicator. Contrib. Mineral. Petrol. 171, 1-15.

Trail, D., Thomas, J.B., Watson, E.B., 2011. The incorporation of hydroxyl into zircon. Am. Mineral. 96, 60-67.

Ushikubo, T., Kita, N.T., Cavosie, A.J., Wilde, S.A., Rudnick, R.L., Valley, J.W., 2008. Lithium in Jack Hills zircons: evidence for extensive weathering of Earth's earliest crust. Earth Planet. Sci. Lett. 272, 666-676.

Watson, E.B., 1996. Dissolution, growth and survival of zircons during crustal fusion: kinetic principles, geological models and implications for isotopic inheritance. Spec. Pap., Geol. Soc. Am. 315, 43-56.

Zhang, Y., 1993. A modified effective binary diffusion model. J. Geophys. Res. - All Series 98, 11,901-11,920.

Zhang, Y., Xu, Z., 2016. Zircon saturation and $\mathrm{Zr}$ diffusion in rhyolitic melts, and zircon growth geospeedometer. Am. Mineral. 101, 1252-1267. 